\title{
Daily settlement variability of the barnacle Semibalanus cariosus: importance of physical factors and density-dependent processes
}

\author{
Takashi Noda*, Kotaro Fukushima, Tsukasa Mori \\ Laboratory of Marine Zoology, Faculty of Fisheries, Hokkaido University, 3-1-1 Minato-cho, Hakodate, Hokkaido 041-8611, Japan
}

\begin{abstract}
Settlement abundances of barnacles are determined by larval supply and the ratio of settlement to larval supply $(K)$. This ratio can be divided into 2 functions: the ratio of settlement on bare space to larval supply $\left(k_{1}\right)$, and the loss of cyprids due to the preempting of rock space by sessile organisms $\left(k_{2}\right)$. To examine the 3 functions of settlement (i.e. larval supply, $k_{1}$ and $k_{2}$ ) of the barnacle Semibalanus cariosus, we monitored the daily water column larval supply and the daily settlement density in plots where all benthos were removed and in natural-community plots, which were left undisturbed, during one settling season. In both low- and mid-tidal sites, $k_{1}$ explained $>75 \%$ of day-to-day variability in K. $k_{1}$ and $k_{2}$ were density dependent, while daily settlement densities were linearly related to larval supply. $k_{1}$ varied with tidal height and daily larval supply, but not with other physical variables. $k_{2}$ varied with daily settlement densities in community-removal plots and was not related to any physical or biological variable. Such density dependence in $k_{1}$ and $k_{2}$ may have been caused by 3 processes: (1) inhibition of larval settlement by planktonic larvae, (2) enhancement of settlement by conspecifics (and their chemical attractants) on days with relatively low larval density, and/or (3) preemption of suitable settlement substrata by settlers that attached on days with relatively high larval density.
\end{abstract}

KEY WORDS: Barnacle . Density dependence $\cdot$ Key factor analysis Settlement

An important advance in marine ecology during the last decade is the realization that limited larval settlement may cause distinct patterns in both population abundance and community organization (Yoshioka 1982, Underwood \& Denley 1984, Gaines \& Roughgarden 1985, Roughgarden et al. 1988, Noda \& Nakao 1996). While recognizing that settlement variation can be caused by variations in larval supply and settlement rate, previous studies have generally focused on these factors separately (e.g. Bertness et al. 1992). Few studies have examined the connection between larval sup-

•E-mail:noda@pop.fish.hokudai.ac.jp ply and settlement in natural habitats (Kendall et al. 1982, Yoshioka 1982, Bertness et al. 1992). Moreover, in those studies, the effects of larval supply on settlement rate were not examined.

In the case of barnacles, settlement abundances are determined by larval supply and the ratio of settlement to larval supply $(K)$. This ratio can be divided into 2 functions: the ratio of settlement on bare space to larval supply $\left(k_{1}\right)$, and the loss of cyprids due to the preempting of rock space by sessile organisms $\left(k_{2}\right)$. To

- examine these 3 functions of settlement (i.e. larval supply, $k_{1}$ and $k_{2}$ ) for the barnacle Semibalanus cariosus, we monitored the water column larval supply and the settlement density daily in plots where all benthos were removed and in plots where the natural community was left undisturbed during one settling season. The objectives of the study were: (1) to relate variation in strength of larval flux (i.e. larval density integrated over the period when the site is immersed) and daily settlement density in undisturbed plots; ${ }_{i}(2)$ to determine the factors causing variations in $k_{1}$ and $k_{2}$ and (3) to determine the relative importance of variations in $k_{1}$ and $k_{2}$ to the ratio of settlement to larval supply by using $k$-factor analysis (Varley \& Gradwell 1960, Podoler \& Rogers 1975, Manly 1990).

Methods. Larval sampling: Larval sampling was carried out daily from 12 April to 29 June 1995 in the intertidal zone of an exposed rocky shore at Usujiri $\left(41^{\circ} 57^{\prime} \mathrm{N}, 140^{\circ} 58^{\prime} \mathrm{E}\right)$, southern Hokkaido, Japan, except when bad weather prevented sampling. Consequently, larval sampling was carried out over $50 \mathrm{~d}$. The sampling period covered most of the settlement season of Semibalanus cariosus (Noda pers. obs.). Planktonic larvae were collected with a centrifugal pump with alternating current (KTZ21-5; Tsurumi) permanently attached on a steep slope of a rock. The pump inflow was located near the lowest water of the spring tide. Daily larval densities (no. $\mathrm{m}^{-3}$ ) were estimated by 
counting the $S$. cariosus cyprids retained on a $0.4 \mathrm{~mm}$ mesh sieve from 540 to $900 \mathrm{l}$ seawater samples collected at low tide during daylight.

Larval supply: We defined daily larval supply at a given site as the larval density integrated over the period in which the site was immersed. To determine the daily larval supply at each settlement site, we multiplied the length of the immersion period at the site within the preceding $24 \mathrm{~h}$ by the larval density determined by sampling on the previous day. We called this measure the cyprid flux index (CFI).

To test the reliability of the CFI as a measure of the daily accumulation of larvae, we obtained a more accurate measure of daily accumulation of larvae (MDAL) by multiplying the length of the immersion period by the mean density of Iarvae collected at $2 \mathrm{~h}$ intervals while the site was immersed. Regression analysis was then preformed for MDAL against CFI. Since the results of the regression analysis supported CFI as an accurate indicator of the daily accumulation of larvae $\left(\mathrm{MDAL}=0.871 \mathrm{CFI}+6.626, \mathrm{R}^{2}=0.992, \mathrm{p}<\right.$ $0.0003, \mathrm{n}=5$ ), we used the CFI to measure the daily accumulation of larvae.

Settlement sampling: Settlement was monitored at 2 sites (i.e. a mid-tidal site and low-tidal site) on a small rock $(1 \times 0.7 \mathrm{~m})$ located $15 \mathrm{~m}$ southwest and inshore of the larval-sampling site. The height of the low-tidal site was approximately $23 \mathrm{~cm}$ lower than that of the mid-tidal site. The distance between the 2 sites was $50 \mathrm{~cm}$. Rock surfaces were smooth and horizontal at both sites. Red algae Gloiopeltis fulcata was the dominant primary space occupier at both sites (cover of G. fulcata was ca $10-25 \%$ in the low-tidal site and ca $1-5 \%$ at the mid-tidal site $\}$. A few Semibalanus cariosus adults were present around the sites (cover $<1 \%)$. The height of the low-tidal site corresponds to the middle of the vertical distribution of settled $S$. cariosus, while the mid-tidal site is near the upper limit of this vertical distribution. The distribution and abundance of sessile organisms at the 2 sites were representative of their respective tidal level.

Four adjoining, permanent $5 \times 5 \mathrm{~cm}$ plots were placed at each site. Two diagonal plots were designated as 'community-removal plots', in which all benthos were removed, while the other 2 were 'naturalcommunity plots', which were undisturbed. In community-removal plots, all organisms were removed from the rock with a scalpel blade or forceps and a wire brush on each sampling date after photographs were taken of the plots. This method can effectively remove all barnacles from the rock. Natural-community plots were left undisturbed.

To quantify the daily settlement densities of metamorphosed barnacles and cyprids, we photographed the plots at low tide during daylight daily from 15 April to 29 June 1995, except when bad weather prevented photography. Consequently, photographs were taken over $47 \mathrm{~d}$ at the low-tidal site and $48 \mathrm{~d}$ at the mid-tidal site. In the plots, daily settlement densities were determined by counting the number of settlers each day. We determined which individuals settled within the previous $24 \mathrm{~h}$ based on comparisons with photographs taken 24 h earlier. We estimated daily settlement densities only when photographs were taken on consecutive days.

To estimate the cover of sessile organisms in the natural-community plots, an acetate peel plate $(5 \times 5 \mathrm{~cm})$ with 100 regularly placed holes was set over the plots. The cover of sessile organisms was determined by counting the number of holes overlying each species. In the natural-community plots, the numbers of accumulated settlers were also counted.

Settlement rate: We defined the ratio of settlement to larval supply at each site as:

$$
\begin{aligned}
K= & \log (\text { chance that planktonic cyprid contact with } \\
& \text { substrata })-\log (\text { settler density in natural habitat) } \\
= & \log (\text { CFI })-\log (S n)
\end{aligned}
$$

where $K=$ ratio of settlement to larval supply, $C F I=$ daily cyprid flux index, and $S n=$ daily settler density in 2 natural-community plots (ind. per $50 \mathrm{~cm}^{2}$ ) at each site.

We divided the ratio of settlement to larval supply into 2 functions. The first is the ratio of settlement on bare space to larval supply:

$$
\begin{aligned}
k_{1}= & \log (\text { chance that planktonic cyprid contact with } \\
& \text { substrata })-\log (\text { settler density in bare space }) \\
= & \log (\text { CFI })-\log (S c r)
\end{aligned}
$$

where $\operatorname{Scr}=$ daily settler density in the 2 communityremoval plots (ind. per $50 \mathrm{~cm}^{2}$ ) at each site.

The second function of the ratio of settlement to larval supply is the loss of cyprids due to the preempting of rock space by sessile organisms:

$$
\begin{aligned}
k_{2}= & \log (\text { settler density in bare space })-\log (\text { settler } \\
& \text { density in natural habitat }) \\
= & \log (S c r)-\log (S n)
\end{aligned}
$$

To divide $K$ into $k_{1}$ and $k_{2}$, we compared settlement in adjacent halves of the treatments within each site (i.e. natural-community plots vs community-removal plots). The plot arrangement was used to minimize the effects of patchy settlement, which can cause differences in settlement densities between treatments within a site.

At both the low-and mid-tidal sites, daily settlement in the 2 community-removal plots was strongly correlated (low-tidal sites: $\mathrm{r}=0.99, \mathrm{p}<0.001, \mathrm{n}=20$; midtidal sites: $r=0.97, \mathrm{p}<0.001, \mathrm{n}=19$ ). This suggests that the effects of patchy settlement on the differences in 
settlement densities between treatments within each site were small.

Environmental variables: The temperature of seawater collected by the larvae-sampling pump was measured daily at 10:00 h. Daily precipitation (09:00 to 21:00 h) was measured at the Usujiri Fisheries Laboratory (ca $50 \mathrm{~m}$ from the sampling site). Daily mean wind force and daily most frequent wind direction were obtained from the Automated Meteorological Data Acquisition System located ca $5 \mathrm{~km}$ from the sampling site.

Results and discussion. In both the low- and midtidal sites, daily settlement in the natural-community plots was significantly correlated to the daily CFI (Fig. 1).

In both the low-and mid-tidal sites, the main factor affecting day-to-day variability in the ratio of settlement to larval supply $(K)$ was not the loss of cyprids due to preempting of rock surfaces by sessile organisms in natural communities $\left(k_{2}\right)$ but the ratio of settlement on bare space to larval supply $\left(k_{1}\right)$ (Table 1$)$. During the study period, the percentage of space occupied by sessile organisms in the community-removal plots was 22 to $52 \%$ in the low-tidal site and 2 to $9 \%$ in the mid-tidal site. This may indicate that $k_{2}$ did not cause the day-to-day variability of $K$, since a lot of free space was available for settlement in the study area. The regression coefficient for $k_{2}$ against $K$ was larger in the low-tidal site than the mid-tidal site (Table 1), indicating that the effects of inhibition of settlement caused by preemption by sessile organisms were stronger in the low-tidal site, where free space was more limited and larvae were more abundant.

$k_{1}$ varied with tidal height and daily CFI and was not related to other physical variables (i.e. seawater temperature, daily precipitation, daily mean wind force and the length of the immersion period at each plot within the previous 24 h) (Table 2, Fig. 2). Day-to-day variability in the larval supply of Semibalanus cariosus

Table 1. Semibalanus cariosus. Key factors during cyprid settlement: ordinary regression coefficients (b) and correlation coefficients ( $\mathrm{r}$ ) for individual mortalities $(k)$ against the ratio of settlement to larval supply $(K) . k_{1}$ : ratio of settlement on bare space to larval supply. $k_{2}$ loss of cyprids due to preemption by sessile organisms. Significant regression coefficients: 0.01 $\leq p<0.05 ; \cdot \cdots 0.001 \leq p<0.01 ; \cdots p<0.001$

\begin{tabular}{|lccc|}
\hline & $\mathrm{b}$ & $\mathrm{r}^{2}$ & $\mathrm{n}$ \\
\hline Low-tidal site & & & \\
$K$ vs $k_{1}$ & $0.753^{\cdots} \cdots$ & 0.725 & 19 \\
$K$ vs $k_{2}$ & $0.247^{-}$ & 0.220 & 19 \\
Mid-tidal site & & & \\
$K$ vs $k_{1}$ & $0.951 \cdots$ & 0.895 & 18 \\
$K$ vs $k_{2}$ & 0.049 & 0.022 & 18 \\
\hline
\end{tabular}

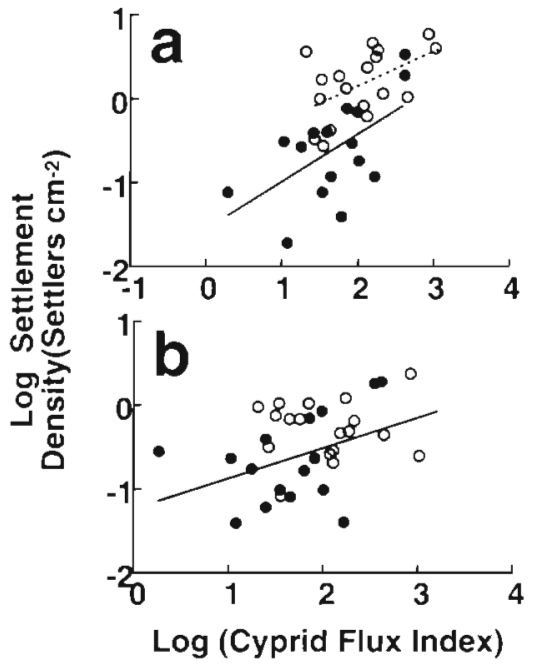

Fig. 1 Semibalanus cariosus. (a) Regression analysis of the daily settlement density in community-removal plots $(y)$ against daily cyprid flux index (x). Dotted line and open circles: relationship in the low-tidal site, $y=-0.667+0.413 x, \mathrm{r}^{2}=$ $0.345, \mathrm{p}=0.016$. $\mathrm{n}=18$. Solid line and filled circles: relationship in the mid-tidal site, $y=-1.566+0.577 x, \mathrm{r}^{2}=0.260, \mathrm{p}=$ $0.031, \mathrm{n}=16$. ANCOVA showed that slopes did not differ $(\mathrm{df}=$ $1.31, p>0.05$ ) but intercepts differed significantly (df $=1,31$, $p=0.0005$ ) between the 2 regressions. (b) Regression analysis of the daily settlement density in natural-community plots $(y)$ against the daily cyprid flux index $(x)$. Open circles: relationshup in the low-tidal site; filled circles: relationship in the midtidal site; for both sites, $y=-1.017+0.300 x, r^{2}=0.135, p=$ $0.033, n=34$. ANCOVA showed that neither slopes nor intercepts differed significantly between the 2 tidal sites $(\mathrm{df}=1,32$,

$$
\mathrm{p}>0.05 \text { ) }
$$

influenced $k_{1}$, suggesting that larval abundance in the water column may inhibit larval settlement (e.g. Crisp \& Meadows 1962, Crisp 1974, Lewis 1978, Minchinton \& Scheibling 1993). The effect of tidal height on $k_{1}$ did not vary with larval supply (i.e. daily CFI), suggesting that selection of the 2 tidal zones by larvae was not affected by larval abundance in the water column.

Table 2. Significant forward selection stepwise multiple regressions for $k_{1}$ against larval supply and physical characteristics between 12 April and 29 June 1995. Significant correlates of $k_{1}$ and the proportion of the variance in the dependent variable $\left(R^{2}\right)$ explained by them in combination are shown. b: regression coefficient; SPRC: standard partial regression coefficient; p: probability (significance: $\cdots 0.001 \leq$ $p<0.01, \cdots p<0.001)$. Independent variables: height and $\log$ (cyprid flux index)

\begin{tabular}{|c|c|c|c|c|c|}
\hline $\begin{array}{l}\text { Dependent } \\
\text { variable }\end{array}$ & Height & $\log (\mathrm{CFI})$ & $\begin{array}{l}\text { Inter- } \\
\text { cept }\end{array}$ & $\mathrm{R}^{2}$ & $\mathrm{n}$ \\
\hline $\begin{array}{ll}k_{1} & b \\
& \text { SPRC } \\
& p\end{array}$ & $\begin{array}{c}0.609 \\
0.567 \\
. .\end{array}$ & $\begin{array}{c}-0.493 \\
0.526 \\
\ldots\end{array}$ & 0.857 & 0.415 & 33 \\
\hline
\end{tabular}




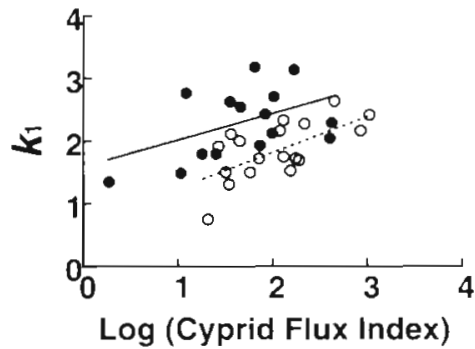

Fig. 2. Semibalanus canosus. Regression analysis of the daily $k_{1}(y)$ against daily cyprid flux index $(x)$. Dotted line and open circles: relationship in the low-tidal site, $y=0.667+0.587 x$, $r^{2}=0.414, p=0.004, n=18$. Solid line and filled circles: relationship in the mid-tidal site, $y=1.476+0.458 x, \mathrm{r}^{2}=0.227, \mathrm{p}=$ $0.06, n=16$. ANCOVA showed that slopes did not differ significantly $(\mathrm{d} f=1,32, \mathrm{p}>0.05)$ but intercepts differed significantly $(\mathrm{df}=1,32, \mathrm{p}=0.0063)$ between the 2 regressions

$k_{2}$ varied with daily settlement densities in community-removal plots (Fig. 3) and was not related to other physical or biological variables (i.e. seawater temperature, daily precipitation, daily mean wind force, tidal height and the length of immersion period at each plot within the previous $24 \mathrm{~h}$, cover of other sessile organisms and density of recruits in the plot on the previous day, cover of other sessile organisms in the 2 naturalcommunity plots on the previous day and density of recruits in the 2 natural-community plots on the previous day). For Semibalanus cariosus, daily settlement densities in community-removal plots influenced $k_{2}$ This density-dependence phenomenon might have been caused by 2 mechanisms. The first is enhancement of settlement by conspecifics (and their chemical attractants) (e.g. Raimondi 1988) on days with relatively low larval settlement. This hypothesis was supported by the fact that settlement density was density dependent and higher in natural-community plots (where conspecifics were present) than in communityremoval plots when the density of settlers in the community-removal plots was low. The second mechanism is the preemption of suitable settlement substrata by settlers that attached on days with relatively high larval settlement. This hypothesis is supported by the fact that settlement densities were density dependent and lower in natural-community plots than in communityremoval plots when the densities of settlers in community-removal plots were high.

Free-space availability affects the settlement of barnacles (e.g. Raimondi 1990, Minchinton \& Scheibling 1993). In this study, however, $k_{2}$ was not related to dayto-day variability of free space. This indicates that the availability of free space was not the cause of the density dependence of $k_{2}$. Alternatively, density-dependent settlement might be due to a shortage of 'suitable settlement sites' (Raimondi 1990). This hypothesis was

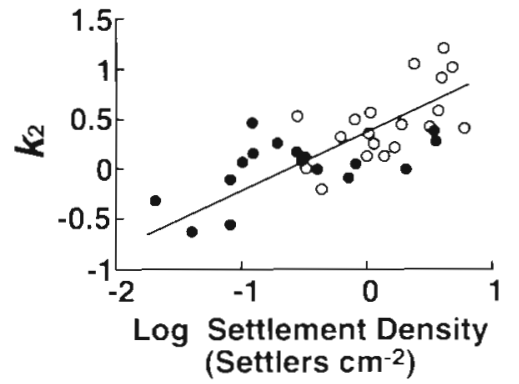

Fig. 3. Semibalanus cariosus. Regression analysis of the daily $k_{2}(y)$ aganst the daily settlement in community-removal plots $(x)$. Open circles: relationship in the low-tidal site; filled circles: relationship in the mid-tidal site; for both sites, $y=$ $0.337+0.432 x, r^{2}=0.478, p=0.0001, n=36$. ANCOVA showed that neither slopes nor intercepts differ significantly ( $\mathrm{df}=1,34, \mathrm{p}>0.05$ ) between the 2 tidal sites

supported by the fact that more than $60 \%$ of settlement occurred repeatedly in a limited area $(1.7 \%$ and $5.9 \%$ of the total quadrat area) of the community-removal plots (Fukushima unpubl. data).

In conclusion, the daily settlement rate of Semibalanus cariosus is density dependent, while daily settlement density is linearly related to larval supply. Such density-dependent settlement rates may be caused by 3 processes: (1) inhibition of larval settlement caused by crowding in the water column, (2) enhancement of settlement by conspecifics (and their chemical attractants) on days of relatively low larval settlement, and/or (3) preemption of suitable settlement substrata by settlers that attached on days with relatively high larval settlement.

Acknowledgements. We thank Dr J. R. Bower and Y Miyamoto for their constructive comments on the manuscript and 4 anonymous referees for their helpful comments. We also thank the Fujiwara Natural History Foundation for their financial support.

\section{LITERATURE CITED}

Bertness MD, Gains SD, Stephens EG, Yund PO (1992) Components of recruitment in populations of the acorn barnacle Semibalanus balanoldes (Linnaeus). J Exp Mar Biol Ecol 156:199-215

Crisp DJ (1974) Factors influencing the settlement of marine invertebrate larvae. In: Grant PT, Mackie AM (eds) Chemoreception in marine organisms. Academic Press, London, p 177-205

Crisp DJ, Meadows DS (1962) The chemical. basis of gregariousness in cirmpedes. Proc R Soc Lond Ser B Biol Sci 156: $500-520$

Gaines S, Roughgarden J (1985) Larval settlement rate: a leading determinant of structure in an ecological community of the marine intertidal zone. Proc Nat Acad Sci USA 82:3707-3711

Kendall MA, Bauman RS, Williamson P, Lewis JR (1982) Settlement patterns, density, and stability in the barnacle BaI- 
anus balanoides. Neth J Sea Res 16:119-126

Lewis CA (1978) A review of substratum selection in free-living and symbiotic cirripeds. In: Chia FS, Rice ME (eds) Settlement and metamorphosis of marine invertebrate larvae. Elsevier/North Holland, New York, p 207-218

Manly BFJ (1990) Stage-structured populations: sampling. analysis and simulation. Chapman and Hall, London

Minchinton TE, Scheibling RE (1993) Free space availability and larval substratum selection as determinants of barnacle population structure in a developing rocky intertidal community. Mar Ecol Prog Ser 95:233-244

Noda T, Nakao S (1996) Dynamics of an entire population of the subtidal snail Umbonium costatum: the importance of annual recruitment fluctuation. J Anim Ecol 65:196-204

Podoler H, Rogers D (1975) A new method for the identification of key factors from life-table data. J Anim Ecol 44: $85-114$

Editorial responsibility: Otto Kinne (Editor),

Oldendort/Luhe, Germany
Raimondi PT (1988) Settlement cues and determination of the vertical limit of an intertidal barnacle. Ecology 69:400-407

Raimondi PT (1990) Patterns, mechanisms, consequences of variability in settlement and recruitment of an intertidal barnacle. Ecol Monogr 60:283-309

Roughgarden J, Gaines S, Possingham H (1988) Recruitment dynamics in complex life cycles. Science 241:1460-1466

Underwood AJ, Denley EJ (1984) Paradigms, explanations, and generalizations in models for the structure of intertidal communities on rocky shores. In: Strong DR, Simberloff $D$, Abele LG, Thistle AB (eds) Ecological communities. Princeton University Pruss, Princeton, p 151-180

Varley GC, Gradwell GR (1960) Key factors in population studies. J Anim Ecol 29:399-401

Yoshioka PM (1982) Role of planktonic and benthic factors in the population dynamics of the briozoan Membranipora menbrancea. Ecology 63:457-468

Submitted: January 12, 1998; Accepted: June 22, 1998

Proofs received from author(s): July 15, 1998 